REVIEW

\title{
Is there a role for treatment of asthma with omalizumab?
}

\section{H Milgrom}

Arch Dis Child 2003;88:71-74

The allergic response is distinct from other immune reactions in its reliance on $\lg \mathrm{E}$, its high affinity receptor, $\mathrm{Fc \in RI}$, and the primary effector cell-the tissue mast cell. Positive skin tests or raised concentrations of specific immunoglobulin $\mathrm{E}(\lg \mathrm{E})$ in the serum define $\lg \mathrm{E}$ sensitisation or "atopy". IgE participates both in immediate hypersensitivity response and in the induction of chronic allergic inflammation. It enhances allergen capture and Th2 cell activation, and may trigger other immunoregulatory pathways. Considerable effort in therapeutic research has focused on interference with $\lg E$ function because of its position high in the allergic cascade. Therapy with anti-lgE is one such approach that shows much promise. authors' affiliation

........

Correspondence to: Prof. H Milgrom, Professor of Pediatrics, National Jewish Medical and Research Center, University of Colorado Health Sciences Center, 1400 Jackson Street, Denver Colorado 80206, USA; milgromh@njc.org

Accepted 5 August 2002
A sthma, a most important cause of chronic disability in childhood, occurs with the highest prevalence in English speaking countries. Recent studies in Britain disclose a self reported rate of $23 \%$ in children aged 6-7 years and $21 \%$ in those aged $12-14 . .^{12}$ In the United States the prevalence of confirmed asthma in children rose from $3.1 \%$ in 1980 to $5.4 \%$ in 1994 , but among impoverished residents of the inner city, the combined prevalence of diagnosed and undiagnosed asthma has been estimated at $26 \%{ }^{3}$ In the USA, deaths from asthma in children under 15 fell from 191 in 1996 to 154 in $1997 .{ }^{4}$ This decrease in mortality may reflect improved management, but it comes short of fulfilling our responsibility to our patients. About one third of children who die from asthma are judged to have mild disease prior to the fatal event. ${ }^{5}$ Preventable causes include inadequate assessment or therapy, poor adherence to therapy, and delay in seeking help. ${ }^{5}$

\section{PATHOGENESIS AND TREATMENT OF ASTHMA IN CHILDHOOD}

A large proportion of all cases of asthma have their onset in the first years of life, but no more than a small minority of infants who wheeze have or will proceed to develop the disease. ${ }^{6}$ Atopy, or the expression of exaggerated IgE antibody responses against common environmental allergens, in early life strongly predicts future airway disease. $^{7-9}$ The link between atopy and asthma lies in the development of persistent inflammation in the airway wall. ${ }^{10}$ As they grow older, those infants with early onset of wheezing who will develop asthma, suffer greater deterioration in lung function and greater persistence of symptoms. ${ }^{11}$ Thus, therapeutic strategies for children should include early anti-inflammatory therapy to prevent progression of the disease. ${ }^{6}$

Asthma is a syndrome characterised by inflammation in medium and small airways that gives rise to constriction and hyperresponsiveness of the bronchial smooth muscle, oedema and disruption of the mucosa, and obstruction of the lumen by mucus. ${ }^{12}{ }^{13}$ The inflammation may lead to airway remodelling with proliferation of airway smooth muscle and deposition of matrix proteins. ${ }^{14}$ There is emerging evidence that airway remodelling may be present very early in disease, even in infancy, ${ }^{15}$ and it may represent a risk factor for the persistence of symptoms and development of asthma. The bronchoconstriction, but not the inflammation, oedema, mucosal injury, or excessive mucus secretion, subsides temporarily after the administration of a bronchodilator. During the past decade national and international bodies, among them the British Thoracic Society, National Heart, Lung, and Blood Institute, and the Global Initiative for Asthma, have convened expert panels charged with developing guidelines to improve the detection and treatment of asthma. ${ }^{16-19}$ These panels expanded the definition of asthma to emphasise airway inflammation and airway hyperresponsiveness over the established focus on reversible obstruction and issued guidelines proposing that pharmacological management target these two processes.

Specific allergen reactivity and raised $\operatorname{IgE}$ are associated with persistent wheezing. ${ }^{20}$ The allergic response differs from other immune reactions by its dependence on IgE, its high affinity receptor, Fc $\in$ RI, and the primary effector cell-the tissue mast cell. Atopy is manifested by positive skin prick tests or measurable specific serum IgE following exposure to a sensitising allergen. Nonatopic individuals, after a similar exposure, typically generate a response characterised by the production of IgGl and IgG4 antibodies. ${ }^{21}{ }^{22}$ Their lymphocytes react in vitro by secreting interferon $\gamma$ by type 1 helper $\mathrm{T}$ (Thl) cells, ${ }^{21}{ }^{23-25}$ rather than interleukin 4 (IL-4) and interleukin-5 (IL-5) produced by the type 2 (Th2) cells in patients with allergic disorders. The reactions following an antigen challenge of a sensitised individual have been designated as early and late phase allergic responses (EPR and LPR). IgE binds to FceRI on inflammatory cells in the airways, the gut, and the skin. Cross linking by allergen molecules of a critical mass of IgE antibodies bound to the

Abbreviations: BDP, beclomethasone dipropionate; EPR, early phase allergic response; $\mathrm{FEV}_{1}$, forced expiratory volume in one second; ICS, inhaled corticosteroid; IL, interleukin; LPR, late phase allergic response 
surface of mast cells initiates EPR. Bronchoconstriction, the clinical manifestation of the EPR in asthma, is confirmed by a fall in forced expiratory volume in 1 second $\left(\mathrm{FEV}_{1}\right)$ within one hour of allergen exposure. ${ }^{26}$ Typically, EPR resolves within an hour of onset.

LPR, thought to reflect clinical exacerbation of asthma, appears as a second episode of airflow obstruction, 4 to 8 hours after antigen exposure. The bronchoconstriction that develops during LPR is more prolonged, and usually more severe, than that observed during EPR. LPR develops as a result of the action of cytokines and chemokines generated by resident inflammatory cells (mast cells, macrophages, and epithelial cells) and recruited inflammatory cells (lymphocytes and eosinophils). ${ }^{26}$ The mast cell is not essential for LPR, however the detection of IL-4, IL-5, IL-6, IL-13, and tumour necrosis factor $\alpha$ in this cell, and their release after the cross linking of $\mathrm{IgE}$, support roles for both IgE and the mast cell in LPR and the ensuing persistent allergic inflammation and bronchial hyperresponsiveness. ${ }^{27}{ }^{28} \mathrm{IgE}$ antibodies are capable of passive transfer of both EPR and LPR sensitivity to allergen challenge. $^{29}$

The identification of IgE receptors on monocytes, eosinophils, dendritic cells, epithelial cells, and platelets along with increased numbers of these receptors in atopic patients suggests a multifunctional role for IgE. ${ }^{30-32}$ Thus, cross linking of IgE bound to FceRI by allergen initiates the release of inflammatory mediators including histamine, leukotrienes, and cytokines and leads to eosinophilic infiltration and inflammation in the affected mucosa or skin. IgE, attached to Fc $\in \mathrm{RII}^{33}$ on activated B cells and antigen presenting cells, such as monocytes and Langerhans cells, enhances allergen capture and Th2 cell activation, both essential processes for initiating and controlling allergic inflammation. ${ }^{21}$ Most interestingly, there is documentation that intrinsic asthma may be associated with local production of $\operatorname{IgE}$ antibodies against unidentified antigens, suggesting that IgE mediated mechanisms may contribute not only to atopic but also to non-atopic disease. $^{34}$

Presently, the most effective treatment for asthma is the administration of inhaled corticosteroids (ICS); however, two time honoured studies conducted in older children exposed some shortcomings of the ICS regimen. One assessed the effect of cessation of treatment in 28 children with stable asthma, aged 11-18, who had completed 28-36 months of therapy with budesonide $200 \mathrm{mg}$ three times daily. ${ }^{35}$ After discontinuation of ICS the children who had been in remission prior to the study deteriorated just as rapidly as those who had not been so stabilised. The second protocol posed the question whether remission can be achieved with long term ICS. ${ }^{36}$ The investigators studied 56 patients using a similar protocol. They found that $60 \%$ of the children had achieved a remission at some time during the trial, but $66 \%$ of them suffered a relapse. These results obtained in children, are supported by a more recent 10 year longitudinal study of 92 asthmatic patients with a mean age of 37 years and a mean duration of disease of 16 years. $^{37}$ Among these patients, 23\% developed nonreversible airflow obstruction in spite of all having received $1500 \mu \mathrm{g}$ of ICS per day and two thirds having received oral corticosteroids in addition. Further insights into therapy with ICS have emerged from the Childhood Asthma Management Program (CAMP). ${ }^{38}$ This study randomly assigned 1041 children, 5-12 years old, with mild to moderate asthma to treatment with ICS, nedocromil, or placebo. The therapy was maintained for five years. ICS led to improvement in measures of asthma control including airway responsiveness, number of hospitalisations and urgent care visits, symptoms, and the need for additional asthma medications, albuterol and prednisone. The benefits of ICS occurred without improvement in lung function as measured by post-bronchodilator $\mathrm{FEV}_{1}$, suggesting that the treatment did not affect the remodelling process. Taken together, these studies show that despite our best efforts, patients with asthma may suffer the consequences of progressive disease inadequately controlled with existing therapies. Holt and Sly have pointed out that the value of new therapeutic agents, which may be capable of blocking the progression from trivial allergy to persistent asthma, is most likely to be recognised if these new drugs are tested in children before their disease becomes permanently established. ${ }^{39}$ The data reviewed above support the need for new therapies to be assessed in children less than 5 years old.

\section{OMALIZUMAB IN THE THERAPY OF ASTHMA}

The avoidance of offending allergens remains a fundamental principle of therapy in patients with allergenic triggers. A pharmacological intervention at the stage of interaction of allergen with IgE first appeared achievable when anti-IgE antibodies were found to suppress both EPR and LPR in mice. ${ }^{40}$ RhuMAb-E25 (now called omalizumab), a murine recombinant monoclonal humanised antibody, was selected for trials in patients with allergic disease. This antibody was found to rapidly reduce free serum IgE, block allergy skin tests in atopic individuals, and significantly suppress EPR, LPR, and sputum eosinophilia in patients with asthma. ${ }^{41}$ Omalizumab lowered free IgE concentrations through the formation of immune complexes with the e 3 domain of the Fc fragment of human IgE. This portion of the IgE molecule binds to the Fc $\in$ RI on inflammatory cells and is not accessible for cross linking on IgE attached to mast cells, ${ }^{42}$ a property necessary in order to avoid bridging of cell bound IgE and initiating the release of inflammatory mediators.

Omalizumab interferes with allergic responses in several ways. (1) It attaches to the FceRI binding domain of free IgE, rendering it unavailable to mast cells to set off EPR. (2) It prevents IgE from interacting with FceRI on monocytes, eosinophils, dendritic cells, epithelial cells, and platelets, thus interfering with mediator/cytokine release and LPR. (3) It prevents IgE from interacting with Fc $\in$ RII on antigen presenting cells. (4) It indirectly causes a notable down-regulation of FceRI on basophils and in all probability other cells. ${ }^{43}(5)$ The effects of IgE-anti-IgE complexes are particularly interesting and potentially beneficial. The non-immunogenic complexes with a half life of about 40 days persist in circulation for a prolonged time. These hexamers have unoccupied antigen binding sites and are able to remove from circulation those allergens against which the patient's IgE is directed. ${ }^{44}{ }^{45}$

In early trials, omalizumab reduced free serum IgE concentrations by more than $90 \%$, considerably suppressed eosinophilia in induced sputum, and blunted both EPR and LPR $^{41}{ }^{46}$ Three published studies involving 1388 patients aged between 11 and 76 years with moderate to severe asthma evaluated treatment with omalizumab using double blind, randomised, placebo controlled clinical protocols. ${ }^{47-49}$ Two of the studies enrolled patients who remained symptomatic despite treatment with systemic or inhaled corticosteroids. ${ }^{48} 49$ All three studies showed that administration of omalizumab resulted in a reduced requirement for corticosteroids and bronchodilators and at the same time enhanced the control of asthma. In each study the observations were supported by improvement in quality of life measurements.

Omalizumab treatment was also evaluated in children who were well controlled on inhaled corticosteroids and as-needed bronchodilators. Three hundred and thirty four children aged 6-12 years, with moderate to severe allergic asthma, were treated with subcutaneously administered placebo $(\mathrm{n}=109)$ or omalizumab $(\mathrm{n}=225)$ at a dose based on body weight and initial serum $\operatorname{IgE}$ concentration $(0.016 \mathrm{mg} / \mathrm{kg} / \mathrm{IgE}$ per four weeks). Beclomethasone dipropionate (BDP) dose (initial range 168-420 mg/day) was kept stable for 16 weeks (stable steroid phase), reduced over eight weeks to the minimum effective dose (steroid reduction phase), and maintained constant for the final four weeks. More subjects in the 
omalizumab group were able to reduce their BDP dose ( $p=0.002)$, compared to those treated with placebo (median reduction $100 \% \vee 66.7 \%, p=0.001$ ). BDP was withdrawn completely in $55 \%$ of patients treated with omalizumab versus $39 \%$ of patients treated with placebo $(p=0.004)$. The incidence and frequency of asthma exacerbations requiring treatment with doubling of BDP dose or systemic corticosteroids were lower in the omalizumab group. The treatment differences were statistically significant during the steroid reduction phase, when fewer subjects in the omalizumab group had asthma exacerbation episodes ( $18.2 \% v 38.5 \%$, $\mathrm{p}<0.001$ ), and the mean number of episodes per patient was smaller than with placebo $(0.42 v 0.72, \mathrm{p}<0.001)$. Five asthma exacerbations requiring hospitalisation all occurred in the placebo group. Over the entire treatment period, patients in the omalizumab group missed a mean of 0.65 school days, compared to a mean of 1.21 days in the placebo group $(p=0.040)$. The mean number of unscheduled medical contacts for asthma related medical problems was significantly smaller in the omalizumab group than in the placebo group throughout the treatment period $(0.15 \vee 0.35$, $\mathrm{p}=0.001)$. Median reduction in serum free IgE was $95-99 \%$ among omalizumab patients. Omalizumab treatment was well tolerated. There were no serious treatment related adverse events. The frequency and types of all adverse events were similar in the omalizumab and placebo groups. ${ }^{50}$

Treatment with omalizumab has been free of serious complications among more than 3000 patients treated to date. One patient who received inhaled therapy developed antibodies to omalizumab, and this mode of delivery has been abandoned. Among patients receiving intravenous therapy, 4\% developed urticaria, usually during the first infusion. With the subcutaneous technique the occurrence was reduced to $2 \%$, no longer limited to the first dose. In October 2000, there were reports of thrombocytopenia in juvenile cynomolgus monkeys treated with omalizumab at doses up to 27 times greater than recommended for clinical use. There were two deaths in animals treated with a more potent anti-IgE antibody that has never been used in clinical trials. However, a search for thrombocytopenia through the records of more than 2000 study patients did not disclose any cases.

\section{CONCLUSION}

We already know that omalizumab is effective for the treatment of allergic rhinitis, ${ }^{5152}$ and most likely for the therapy and prevention of anaphylaxis, food allergy, and atopic dermatitis. Although atopy may be a parallel rather than sequential factor in the pathogenesis of asthma, ${ }^{53}$ there is sound evidence that manifestation of the disease is associated with specific IgE antibodies. Omalizumab decreases free IgE, suppresses both early and late phase allergic reactions, improves symptoms, stabilises lung function, and reduces the need for corticosteroids. However, longer term studies are needed to determine the best selection of patients for treatment and the duration of beneficial effect, and, most importantly, to answer the question whether omalizumab arrests disease progression.

Current pharmacotherapy decreases inflammation and provides symptomatic relief, but it does not entirely suppress the underlying disease, and new approaches are still needed. Further, there are some patients for whom existing medical regimens are not satisfactory. Omalizumab should be evaluated in the treatment of children who require unacceptably high doses of oral or inhaled corticosteroids and those who are suffering from steroid induced side effects. In certain patients uncontrolled asthma is associated with reduced glucocorticoid receptor binding within the inflammatory cells. ${ }^{54}$ Frequent exacerbations and increased mortality have been documented in patients who do not adhere to their treatment regimen, ${ }^{55}$ while in others, imperfect effort and technique limit the effectiveness of inhaled medications. Thus, there are still patients with asthma who stand in need of new therapies to overcome problems that remain uncontrolled. Omalizumab may offer new hope for them.

"As for the future our task is not to foresee it but to enable it" (St Exupery)

\section{REFERENCES}

1 Shamssain $\mathbf{M H}$, Shamsian N. Prevalence and severity of asthma rhinitis, and atopic eczema: the north east study. Arch Dis Child 1999:81:313-17.

2 Kaur B, Anderson HR, Austin J, et al. Prevalence of asthma symptoms, diagnosis, and treatment in 12-14 year old children across Great Britain (international study of asthma and allergies in childhood, ISAAC UK). BM 1998;316:1 18-24.

3 Sly RM. Changing prevalence of allergic rhinitis and asthma. Ann Allergy Asthma Immunol 1999:82:233-48, quiz 248-52.

4 Sly RM. Decreases in asthma mortality in the United States. Ann Allergy Asthma Immunol 2000;85: 121-7.

5 Robertson CF, Rubinfeld AR, Bowes G. Pediatric asthma deaths in Victoria: the mild are at risk. Pediatr Pulmonol 1992;13:95-100.

6 Milgrom H. Drug treatment of wheezy infants. In: David T, ed. Recent advances in paediatrics. London: Churchill Livingstone, 2001:27-42.

7 Illi S, von Mutius E, Lau S, et al. The pattern of atopic sensitization is associated with the development of asthma in childhood. J Allergy Clin Immunol 2001;108:709-14.

8 Haby MM, Peat JK, Marks GB, et al. Asthma in preschool children: prevalence and risk factors. Thorax 2001;56:589-95.

9 Rhodes HL, Sporik R, Thomas P, et al. Early life risk factors for adult asthma: a birth cohort study of subjects at risk. J Allergy Clin Immunol 2001:108:720-5.

10 Holt PG, Macaubas C, Stumbles PA, et al. The role of allergy in the development of asthma. Nature 1999;402(6760 suppl):B12-17.

11 Martinez FD. Present and future treatment of asthma in infants and young children. J Allergy Clin Immunol 1999;104(4 pt 2): 169-74.

12 Holgate ST, Frew AJ. Choosing therapy for childhood asthma. N Engl J Med 1997;337: 1690-2

13 Hamid Q, Song Y, Kotsimbos TC, et al. Inflammation of small airways in asthma. J Allergy Clin Immunol 1997;100:44-51.

14 Redington AE, Howarth PH. Airway wall remodelling in asthma. Thorax 1997;52:310-12.

15 Helms PJ. Early environmental influences in the development of asthma and atopic disease. Monaldi Arch Chest Dis 2001;56:265-9

16 GINA. Practical guide for asthma management. http:// www.ginasthma.com:80/xprac.html, 1995

17 National Institutes of Health, National Heart, Lung, and Blood Institute. National Asthma Education and Prevention Program. Expert Panel Report 2: Guidelines for the diagnosis and management of asthma Publication No. 97-4051, 1997.

18 British Thoracic Society. The British guidelines on asthma management: 1995 review and position statement. Thorax 1997;52:S1-21.

19 Warner JO, Naspitz CK. Third International Pediatric Consensus statement on the management of childhood asthma. International Pediatric Asthma Consensus Group. Pediatr Pulmonol 1998;25:1-17.

20 Stein RT, Holberg CJ, Morgan WJ, et al. Peak flow variability, methacholine responsiveness and atopy as markers for detecting different wheezing phenotypes in childhood. Thorax 1997;52:946-52.

21 Kay AB. Allergy and allergic diseases. First of two parts. N Engl J Med 2001;344:30-7.

22 Kemeny DM, Urbanek R, Ewan $P$, et al. The subclass of $\lg G$ antibody in allergic disease: II. The lgG subclass of antibodies produced following natural exposure to dust mite and grass pollen in atopic and non-atopic individuals. Clin Exp Allergy 1989;19:545-9.

23 Romagnani S. Human $\mathrm{TH} 1$ and $\mathrm{TH} 2$ subsets: doubt no more. Immunol Today $1991: 12: 256-7$

24 Ebner C, Schenk S, Najafian N, et al. Nonallergic individuals recognize the same T cell epitopes of Bet $v 1$, the major birch pollen allergen, as atopic patients. J Immunol 1995;154:1932-40.

25 Till S, Durham S, Dickason R, et al. IL-13 production by allergen-stimulated T cells is increased in allergic disease and associated with IL-5 but not IFN-gamma expression. Immunology 1997;91:53-7.

26 Busse WW, Lemanske RF Jr. Asthma. N Engl J Med 2001;344:350-62

27 Bradding $\mathbf{P}$, Roberts JA, Britten KM, et al. Interleukin- $4,-5$, and -6 and tumor necrosis factor-alpha in normal and asthmatic airways: evidence for the human mast cell as a source of these cytokines. Am J Respir Cell Mol Biol 1994; 10:471-80.

28 Pawankar RU, Okuda M, Hasegawa S, et al. Interleukin-13 expression in the nasal mucosa of perennial allergic rhinitis. Am J Respir Crit Care Med 1995;152(6 pt 1):2059-67.

29 Oettgen HC, Geha RS. IgE in asthma and atopy: cellular and molecular connections. J Clin Invest 1999; 104:829-35.

30 Ying S, Barata LT, Meng Q, et al. High-affinity immunoglobulin E receptor (Fc epsilon RI)-bearing eosinophils, mast cells, macrophages and Langerhans' cells in allergen- induced late-phase cutaneous reactions in atopic subjects. Immunology 1998;93:281-8. 
31 Sihra BS, Kon OM, Grant JA, et al. Expression of high-affinity lgE receptors (Fc epsilon RI) on peripheral blood basophils, monocytes, and eosinophils in atopic and nonatopic subjects: relationship to total serum IgE concentrations. J Allergy Clin Immunol 1997;99:699-706.

32 Rajakulasingam K, Durham SR, O'Brien F, et al. Enhanced expression of high-affinity lgE receptor (Fc epsilon RI) alpha chain in human allergen-induced rhinitis with co-localization to mast cells, macrophages, eosinophils, and dendritic cells. J Allergy Clin Immuno 1997:100:78-86.

33 Armitage RJ, Goff LK. Functional interaction between B cell subpopulations defined by CD23 expression. Eur J Immunol 1988;18:1753-60.

34 Menz G, Ying S, Durham SR, et al. Molecular concepts of IgE-initiated inflammation in atopic and nonatopic asthma. Allergy 1998:53:15-21.

35 Waalkens HJ, Van Essen-Zandvliet EE, Hughes MD, et al. Cessation of long-term treatment with inhaled corticosteroid (budesonide) in children with asthma results in deterioration. The Dutch CNSLD Study Group. Am Rev Respir Dis 1993;148:1252-7.

36 van Essen-Zandvliet EE, Hughes MD, Waalkens HJ, et al. Remission of childhood asthma after long-term treatment with an inhaled corticosteroid (budesonide): can it be achieved? Dutch CNSLD Study Group. Eur Respir J 1994;7:63-8

37 Ulrik CS, Backer V. Nonreversible airflow obstruction in life-long nonsmokers with moderate to severe asthma. Eur Respir J 1999;14:892-6.

38 The Childhood Asthma Management Program Research Group. Long-term effects of budesonide or nedocromil in children with asthma. $N$ Engl J Med 2000;343: 1054-63

39 Holt PG, Sly PD. Prevention of adult asthma by early intervention during childhood: potential value of new generation immunomodulatory drugs. Thorax 2000;55:700-3.

40 Shields RL, Whether WR, Zioncheck K, et al. Inhibition of allergic reactions with antibodies to IgE. Intern Arch Allergy Immunol 1995; 107:308-12.

41 Fahy J, Fleming $\mathrm{H}$, Wong $\mathrm{H}$, et al. The effect of an anti-lgE monoclonal antibody on the early and late phase responses to allergen inhalation in asthmatic subjects. Am J Respir Crit Care Med 1997; 155: 1828-34.

42 Presta L, Gorman C, Shields R, et al. The binding site on human immunoglobulin $\mathrm{E}$ for its high affinity receptor. J Biol Chem 1994;269:26368-73.
43 MacGlashan DW Jr, Bochner BS, Adelman DC, et al. Down-regulation of Fc(epsilon)RI expression on human basophils during in vivo treatment of atopic patients with anti-lgE antibody. J Immunol 1997; 158: 1438-45.

44 Chang TW. The pharmacological basis of anti-lgE therapy. Nat Biotechnol 2000;18:157-62.

45 Milgrom $\mathbf{H}$. Attainments in atopy: special aspects of allergy and $\lg E$. Adv Pediatr. In press.

46 Boulet L, Chapman K, Cote J, et al. Inhibitory effects of an anti-lgE antibody E25 on allergen-induced early asthmatic response. Am J Respir Crit Care Med 1997;155:1835-40.

47 Milgrom H, Fick RB Jr, Su JQ, et al. Treatment of allergic asthma with monoclonal anti-lgE antibody. rhuMAb- E25 Study Group. N Engl J Med 1999;341:1966-73.

48 Busse W, Corren J, Lanier BQ, et al. Omalizumab, anti-lgE recombinant humanized monoclonal antibody, for the treatment of severe allergic asthma. J Allergy Clin Immunol 2001;108:184-90.

49 Soler M, Matz J, Townley R, et al. The anti-lgE antibody omalizumab reduces exacerbations and steroid requirement in allergic asthmatics. Eur Respir J 2001;18:254-61.

50 Milgrom H, Berger W, Nayak A, et al. Treatment of childhood asthma with anti-immunoglobulin $\mathrm{E}$ antibody (omalizumab). Pediatrics 2001;108:E36

51 Adelroth E, Rak S, Haahtela T, et al. Recombinant humanized mAb-E25, an anti-lgE $\mathrm{mAb}$, in birch pollen-induced seasonal allergic rhinitis. J Allergy Clin Immunol 2000;106:253-9.

52 Casale TB, Condemi J, LaForce C, et al. Effect of omalizumab on symptoms of seasonal allergic rhinitis: a randomized controlled trial. JAMA 2001;286:2956-67.

53 Holgate ST, Lackie PM, Howarth PH, et al. Invited lecture: activation of the epithelial mesenchymal trophic unit in the pathogenesis of asthma. Int Arch Allergy Immunol 2001;124:253-8.

54 Sher ER, Leung DY, Surs W, et al. Steroid-resistant asthma. Cellular mechanisms contributing to inadequate response to glucocorticoid therapy. J Clin Invest 1994;93:33-9.

55 Milgrom H, Bender B, Ackerson L, et al. Non-compliance and treatment failure in children with asthma. J Allergy Clin Immunol 1996;98: 1051-7. 